\title{
Efficacy and Safety of Acupuncture Therapy for Patients with Acute Ankle Sprain: A Systematic Review and Meta-Analysis of Randomized Controlled Trials
}

\author{
Ai-Feng Liu $\left(\mathbb{D},{ }^{1}\right.$ Shu-Wei Gong $\mathbb{D}^{2},{ }^{2}$ Ji-Xin Chen $\left(\mathbb{D},{ }^{1}\right.$ and Jing-Bo Zhai ${ }^{3}{ }^{3}$ \\ ${ }^{1}$ Department of Orthopaedic Surgery, First Teaching Hospital of Tianjin University of Traditional Chinese Medicine, \\ Tianjin, China \\ ${ }^{2}$ Graduate College, Tianjin University of Traditional Chinese Medicine, Tianjin, China \\ ${ }^{3}$ Institute of Traditional Chinese Medicine, Tianjin University of Traditional Chinese Medicine, Tianjin, China \\ Correspondence should be addressed to Ai-Feng Liu; draifeng@163.com and Jing-Bo Zhai; zhaijingbo@foxmail.com
}

Received 13 February 2020; Revised 14 September 2020; Accepted 26 September 2020; Published 16 October 2020

Academic Editor: José L. Rios

Copyright (c) 2020 Ai-Feng Liu et al. This is an open access article distributed under the Creative Commons Attribution License, which permits unrestricted use, distribution, and reproduction in any medium, provided the original work is properly cited.

Background. The efficacy of acupuncture for acute ankle sprain (AAS) is controversial. This study aimed to critically assess the efficacy and safety of acupuncture for AAS. Methods. Parallel-group randomized controlled trials (RCTs) were included regardless of language or publication date. Participants with AAS were included regardless of age, sex, race, nationality, or diagnostic criteria for AAS. Experimental interventions included acupuncture alone or in combination with traditional therapies. Control interventions included no treatment, placebo, or traditional therapies. The primary outcome was the Kofoed ankle score. The secondary outcomes included visual analogue scale, duration of pain, use of painkiller, ankle circumference, effective rate, cure rate, and adverse events. PubMed, Embase, Cochrane Library, Web of Science, China National Knowledge Infrastructure, Wanfang Digital Periodicals, and Chinese Science and Technology Periodicals database were searched to identify potentially eligible studies from inception to September 10, 2020. World Health Organization International Clinical Trials Registry Platform (WHO ICTRP), ClinicalTrials.gov, Chinese Clinical Trial Registry (ChiCTR), and the reference list of eligible RCTs were checked to identify ongoing or unpublished studies. Risk of bias was assessed by the Cochrane Collaboration's tool. Statistical analyses were performed by RevMan 5.3 software. $P<0.05$ indicated statistical significance. Results. Seventeen eligible studies were included for the statistical analysis. There was no statistically significant difference of Kofoed ankle score between acupuncture and Rest, Ice, Compression, and Elevation (RICE) group $(P=0.75)$. However, acupuncture could significantly relieve pain $(P=0.02)$ and increase cure rate $(P=0.004)$ compared with RICE. Moreover, acupuncture plus RICE could also significantly relieve pain $(P<0.00001)$ and increase cure rate $(P=0.01)$ compared with RICE alone. Acupuncture combined with massage could significantly relieve pain $(P=0.04)$ compared with massage alone. Acupuncture plus Chinese medicine might be more effective for relieving pain $(P<0.00001)$, reducing the duration of pain $(P<0.00001)$, and increasing cure rate $(P=0.0002)$ compared with Chinese medicine alone. Two studies reported no adverse reactions. One study reported that a participant suffered from mild drug-related allergic reaction and was healed without treatment. Conclusions. The findings of the present study suggest that acupuncture may be beneficial for AAS. However, more large-scale and well-designed RCTs are warranted.

\section{Introduction}

Acute ankle sprain (AAS) is defined as an acute injury of the ankle ligament [1]. Ankle sprain is one of the major injuries among the general population and athletes [2-4]. AAS may result in acute pain, swelling, high cost, chronic ankle instability, etc. $[5,6]$. There are a variety of therapeutic interventions for AAS, involving pharmacological therapies (e.g., nonsteroidal anti-inflammatory drugs) and nonpharmacological therapies (e.g., functional support, exercise, and manual mobilization) [3, 4]. However, no optimal therapies were recommended for 
treating AAS according to a latest evidence-based clinical guideline [4].

Acupuncture belongs to complementary and alternative medicine and is commonly used for relieving acute and chronic pain [7, 8]. Two previous systematic reviews assessed the efficacy of acupuncture for ankle sprain [1,9]. However, the evidence on acupuncture for ankle sprain still remains inconclusive because of large heterogeneity [4]. There are some methodological flaws in the two previous studies $[1,9]$. For example, high clinical heterogeneity might be caused by combining results from studies involving patients with acute and chronic ankle sprain. Different types of acupuncture resulted in the heterogeneity of interventions. Moreover, some new trials of acupuncture for AAS have been published in recent years [10-17]. However, the evidence has not been critically assessed. Therefore, we conducted an updated systematic review to assess the efficacy and safety of acupuncture for AAS.

\section{Methods}

This systematic review was registered on PROSPERO (no. CRD42020156280). It was conducted in compliance with the Preferred Reporting Items for Systematic Reviews and MetaAnalyses (PRISMA) statement [18].

\subsection{Inclusion and Exclusion Criteria}

2.1.1. Types of Studies. Parallel-group randomized controlled trials (RCTs) were included regardless of language or publication date.

2.1.2. Types of Participants. Participants with AAS were included regardless of age, sex, race, nationality, or diagnostic criteria for AAS.

2.1.3. Types of Interventions. The experimental interventions included acupuncture alone or in combination with traditional therapies. The control interventions included no treatment, placebo, or traditional therapies. Traditional therapies for acute ankle sprain involve nonsteroidal antiinflammatory drugs, Rest, Ice, Compression, and Elevation (RICE), functional support, exercise, manual mobilization, etc. There were no restrictions on frequency or duration of acupuncture. The following comparisons were considered if possible: (1) acupuncture alone versus no treatment/placebo/traditional therapies; (2) acupuncture plus traditional therapies versus traditional therapies alone; and (3) acupuncture plus traditional therapies versus traditional therapies plus placebo.

2.1.4. Types of Outcomes. The primary outcome was the Kofoed ankle score. The secondary outcomes included visual analogue scale (VAS), duration of pain, use of painkiller, ankle circumference, effective rate, cure rate, and adverse events. Kofoed ankle score is comprised of pain, function, and mobility domain and ranges from 0 to 100 with higher score indicating less pain [19]. VAS ranges from 0 to 10 or 100 with higher score indicating more severe pain.

2.2. Search Strategy. Two authors (SWG and AFL) independently searched PubMed, Embase, Cochrane Library, Web of Science, China National Knowledge Infrastructure, Wanfang Digital Periodicals, and Chinese Science and Technology Periodicals database from inception to September 10, 2020, to identify potentially eligible studies. World Health Organization International Clinical Trials Registry Platform (WHO ICTRP), ClinicalTrials.gov, Chinese Clinical Trial Registry (ChiCTR), and the reference list of eligible RCTs were checked to identify ongoing or unpublished studies [20]. The detailed search strategy is available in Supplementary Material.

2.3. Selection of Studies and Data Extraction. All studies identified from the electronic search were imported into EndNote software. Two reviewers (SWG and AFL) independently checked the title and abstract to remove duplicates and irrelevant studies. Full texts of the remaining studies were read to identify potentially eligible studies. The selection process was summarized using a PRISMA flow diagram.

The following information was extracted independently by two reviewers (JXC and SWG). Disagreements were resolved by consensus or consultation with a third review author (JBZ).

(1) Study details: title, first author, country, year of publication, design, methods of randomization, allocation, and blinding

(2) Patients: age, sample size

(3) Interventions: type, frequency, and duration

(4) Outcome measures: Kofoed ankle score, VAS, duration of pain, use of painkiller, ankle circumference, effective rate, cure rate, and adverse events

2.4. Assessment of Risk of Bias. Two reviewers (JXC and SWG) independently assessed the risk of bias in eligible studies using the Cochrane Collaboration's tool [21, 22]. It includes seven important items: random sequence generation, allocation concealment, blinding of participants and personnel, blinding of outcome assessment, incomplete outcome data, selective outcome reporting, and other potential sources of bias. The risk of bias for each item was classified as low, high, or unclear. The results were presented with risk of bias graph and summary figure.

2.5. Statistical Analysis. Mean difference (MD) with $95 \%$ confidence intervals (CIs) was calculated for continuous variables if the same tool was used to measure a certain outcome across different studies. Otherwise, standardized mean difference (SMD) was calculated. Risk ratio (RR) with 95\% CIs was used for dichotomous variables. If clinical heterogeneity was low, meta-analysis was used to estimate 
the overall effect. Statistical heterogeneity was evaluated by chi-square test or $I^{2}$ statistics. If the $P$ value of chi-square test was greater than 0.10 or $I^{2}$ was less than $50 \%$, the fixed-effect model was used to estimate the effect size. Otherwise, the random-effect model was used. The funnel plot was used to assess publication bias when at least 10 studies were included in a meta-analysis. Subgroup analyses were performed based on intervention and comparison if possible. RevMan 5.3 software was used for the statistical analysis. $P<0.05$ indicated statistical significance. If performing meta-analysis was infeasible, a narrative description was provided.

\section{Results}

3.1. Literature Search. The initial search yielded 1857 potentially eligible studies. We deleted 540 duplicates and 1264 irrelevant studies by checking the title and abstract. After reading full texts of the remaining records, 36 studies were excluded. Finally, 17 studies [10-17, 23-31] were included for the statistical analysis (Figure 1).

3.2. Characteristics of Included Studies. The characteristics of the included studies are summarized in Table 1. Seventeen studies involving 1528 patients were published between 1999 and 2018 in China. Sample size ranged from 20 to 90 in the experimental group and 20 to 70 in the control group. Experimental interventions included acupuncture alone or in combination with RICE, dimethyl sulfoxide, Chinese medicine, or massage. Control interventions included RICE, dimethyl sulfoxide, Chinese medicine, massage, ice and hot pack, no treatment, or infrared radiation.

3.3. Assessment of Risk of Bias. Risk of bias graph and summary are presented in Figures 2 and 3. Five trials [11, 14-17] used a random number table, one [25] used coin tossing, and one [28] used a computer random number generator to generate a random sequence. One study [30] used sealed envelopes to conceal allocation. Attrition bias was low because complete outcome data were reported in all included studies. Performance bias, detection bias, reporting, bias, and other bias were unclear because of insufficient information.

3.4. Kofoed Ankle Score. One study [12] reported the response rate of Kofoed ankle score. Response was defined as having a Kofoed ankle score greater than or equal to 75 . It indicated that no statistically significant difference was found between acupuncture and RICE group $(n=60$, $\mathrm{RR}=1.04,95 \% \mathrm{CI}: 0.80$ to $1.36, P=0.75)$.

3.5. Visual Analogue Scale. Narrative analyses were provided because of the heterogeneity of interventions. $\mathrm{Wu}$ [28] found that acupuncture could significantly relieve pain compared with no treatment $(n=61, \mathrm{MD}=-6.92,95 \% \mathrm{CI}:-7.33$ to -6.51, $P<0.00001)$. Li [12] found that acupuncture was superior to RICE for pain relief $(n=60, \mathrm{MD}=-0.37,95 \% \mathrm{CI}$ : -0.67 to $-0.07, P=0.02)$. Wu et al. [16] reported that

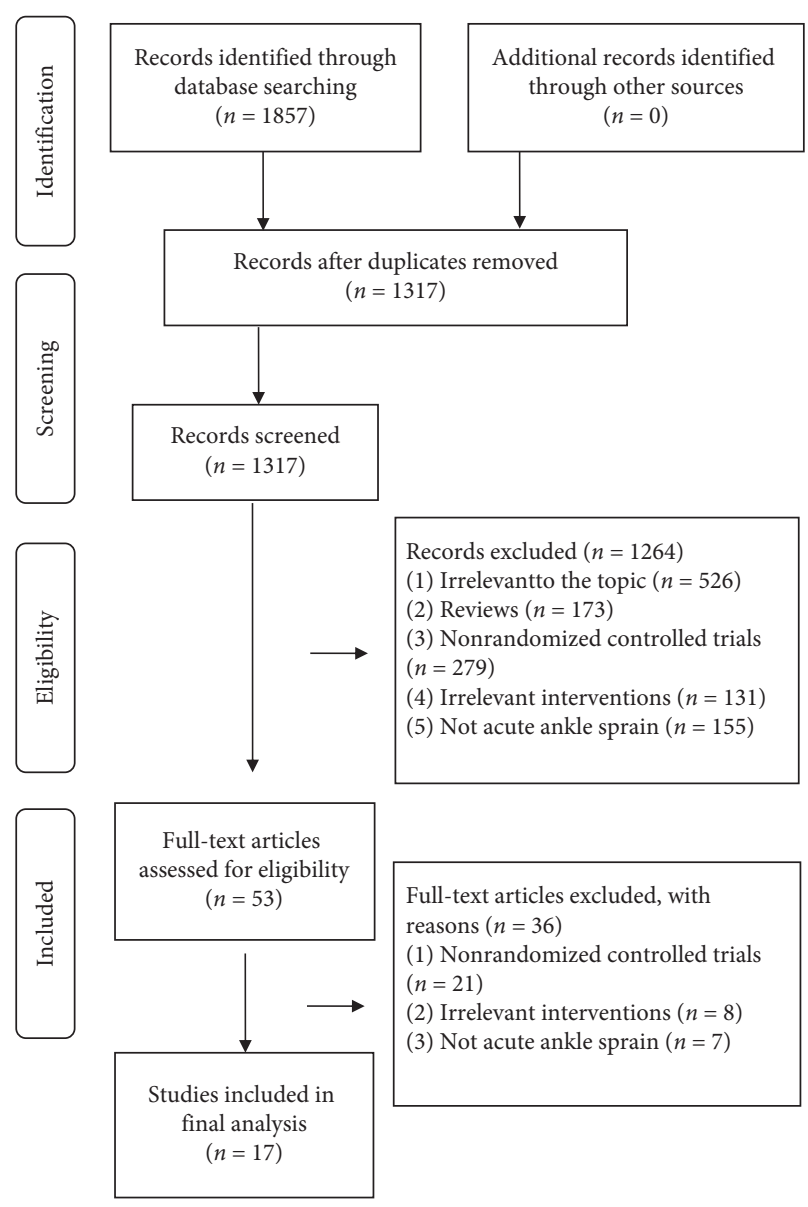

Figure 1: Flow diagram for study retrieval and selection.

acupuncture plus RICE achieved a greater level of pain relief than RICE $(n=90, \mathrm{MD}=-1.14,95 \% \mathrm{CI}:-1.63$ to -0.65 , $P<0.00001)$. Wu et al. [15] showed that acupuncture plus massage could significantly decrease the VAS score compared with massage alone $(n=82, \mathrm{MD}=-0.26,95 \% \mathrm{CI}$ : -0.51 to $-0.01, P=0.04)$. Zou et al. [13] reported that acupuncture plus Chinese medicine could significantly relieve pain compared with Chinese medicine alone $(n=40$, $\mathrm{MD}=-2.73,95 \% \mathrm{CI}:-2.89$ to $-2.57, P<0.00001)$.

3.6. Duration of Pain. Li et al. [17] found that acupuncture plus Chinese medicine was more effective than Chinese medicine alone for reducing the duration of pain $(n=80$, $\mathrm{MD}=-2.50,95 \% \mathrm{CI}:-2.97$ to $-2.03, P<0.00001)$. Sun et al. [30] reported that acupuncture could significantly reduce the duration of pain compared with elastoplast $(n=82$, $\mathrm{MD}=-3.40,95 \% \mathrm{CI}:-3.88$ to $-2.92, P<0.00001)$.

3.7. Use of Painkillers. Wu et al. [15] found no significant difference of use of painkillers between acupuncture plus massage and massage alone $(n=82, \mathrm{RR}=0.48,95 \% \mathrm{CI}: 0.16$ to $1.46, P=0.19)$. 
TABLE 1: Characteristics of included studies.

\begin{tabular}{|c|c|c|c|c|c|c|c|}
\hline $\begin{array}{l}\text { First } \\
\text { author }\end{array}$ & Year & $\begin{array}{c}\text { Sample } \\
\text { size }(\mathrm{E} / \mathrm{C})\end{array}$ & Experimental interventions & Control interventions & $\begin{array}{l}\text { Frequency of } \\
\text { acupuncture }\end{array}$ & $\begin{array}{l}\text { Duration of } \\
\text { acupuncture }\end{array}$ & Outcomes \\
\hline $\begin{array}{l}\mathrm{Yu}(1) \\
{[23]}\end{array}$ & 1999 & $\begin{array}{l}30 \text { in each } \\
\text { group } / 30 \\
\text { in each } \\
\text { group }\end{array}$ & $\begin{array}{c}\text { Acupuncture; } \\
\text { acupuncture + RICE(ice } \\
\text { pack) + dimethyl sulfoxide }\end{array}$ & $\begin{array}{l}\text { RICE(ice pack); } \\
\text { dimethyl sulfoxide }\end{array}$ & Twice a day & 7 days & Effective rate \\
\hline $\begin{array}{l}\text { Yu }(2) \\
{[24]}\end{array}$ & 1999 & $\begin{array}{l}50 \text { in each } \\
\text { group } / 50\end{array}$ & $\begin{array}{c}\text { Acupuncture; } \\
\text { acupuncture + dimethyl } \\
\text { sulfoxide }\end{array}$ & Dimethyl sulfoxide & Not reported & 7 days & Effective rate \\
\hline $\begin{array}{l}\text { Jiao and } \\
\text { Wang } \\
{[25]}\end{array}$ & 2004 & $48 / 48$ & $\begin{array}{c}\text { Acupuncture }+ \text { Chinese } \\
\text { medicine (shujin huoxue } \\
\text { pill }+ \text { jiejing zhitong tincture) }\end{array}$ & $\begin{array}{l}\text { Chinese medicine } \\
\text { (shujin huoxue } \\
\text { pill + jiejing zhitong } \\
\text { tincture) }\end{array}$ & Once a day & 7 days & $\begin{array}{c}\text { Effective rate, cure } \\
\text { rate }\end{array}$ \\
\hline $\begin{array}{l}\text { Wang } \\
{[26]}\end{array}$ & 2005 & $27 / 30$ & Acupuncture & Infrared radiation & Once a day & 5 days & $\begin{array}{l}\text { Effective rate, cure } \\
\text { rate }\end{array}$ \\
\hline $\begin{array}{l}\text { Hao and } \\
\text { Wang } \\
{[27]}\end{array}$ & 2006 & $63 / 63$ & $\begin{array}{l}\text { Acupuncture }+ \text { Chinese } \\
\text { medicine (herbs) }\end{array}$ & $\begin{array}{l}\text { Chinese medicine } \\
\text { (herbs) }\end{array}$ & $\begin{array}{l}\text { Once two } \\
\text { days }\end{array}$ & 7 days & $\begin{array}{l}\text { Effective rate, cure } \\
\text { rate }\end{array}$ \\
\hline $\mathrm{Wu}[28]$ & 2007 & $31 / 30$ & Acupuncture & No treatment & Once a day & 5 days & $\begin{array}{c}\text { Effective rate, cure } \\
\text { rate, VAS }\end{array}$ \\
\hline $\begin{array}{l}\mathrm{Ni} \text { and } \\
\mathrm{Li}[29]\end{array}$ & 2010 & $64 / 59$ & Acupuncture & $\begin{array}{l}\text { Ice and hot } \\
\text { pack }+ \text { Chinese } \\
\text { medicine }\end{array}$ & Once a day & 3 days & $\begin{array}{c}\text { Effective rate, cure } \\
\text { rate }\end{array}$ \\
\hline $\begin{array}{l}\text { Sun and } \\
\mathrm{Ju}[30]\end{array}$ & 2011 & $41 / 41$ & Acupuncture & RICE (elastoplast) & Once a day & 14 days & $\begin{array}{l}\text { Effective rate, cure } \\
\text { rate, duration of } \\
\text { pain }\end{array}$ \\
\hline $\begin{array}{l}\text { Zhang } \\
\text { and } \\
\text { Zhang } \\
{[31]}\end{array}$ & 2011 & $90 / 70$ & $\begin{array}{l}\text { Acupuncture }+ \text { Chinese } \\
\text { medicine (qili powder) }\end{array}$ & $\begin{array}{l}\text { Chinese medicine } \\
\text { (qili powder) }\end{array}$ & Once a day & 10 days & $\begin{array}{c}\text { Effective rate, cure } \\
\text { rate }\end{array}$ \\
\hline Suo $[10]$ & 2014 & $36 / 35$ & $\begin{array}{l}\text { Acupuncture }+ \text { Chinese } \\
\text { medicine (yunnan baiyao } \\
\text { tincture) }\end{array}$ & $\begin{array}{l}\text { Chinese medicine } \\
\text { (yunnan baiyao } \\
\text { tincture) }\end{array}$ & Not reported & Not reported & $\begin{array}{c}\text { Effective rate, cure } \\
\text { rate }\end{array}$ \\
\hline $\mathrm{Du}[11]$ & 2014 & $\begin{array}{l}20 \text { in each } \\
\text { group } / 20\end{array}$ & $\begin{array}{c}\text { Acupuncture; } \\
\text { acupuncture + massage }\end{array}$ & Massage & Once a day & 3 days & $\begin{array}{l}\text { Effective rate, cure } \\
\text { rate }\end{array}$ \\
\hline $\operatorname{Li}[12]$ & 2016 & $30 / 30$ & Acupuncture & RICE & Once a day & 7 days & $\begin{array}{l}\text { VAS, Kofoed ankle } \\
\text { score, ankle } \\
\text { circumference }\end{array}$ \\
\hline Zou [13] & 2016 & $20 / 20$ & $\begin{array}{l}\text { Acupuncture }+ \text { Chinese } \\
\text { medicine (sunshang } \\
\text { emplastrum) }\end{array}$ & $\begin{array}{l}\text { Chinese medicine } \\
\text { (sunshang } \\
\text { emplastrum) }\end{array}$ & $\begin{array}{l}\text { Once two } \\
\text { days }\end{array}$ & 7 days & $\begin{array}{l}\text { VAS, effective rate, } \\
\text { cure rate }\end{array}$ \\
\hline $\begin{array}{l}\text { Pei and } \\
\text { Wei }[14]\end{array}$ & 2017 & $35 / 35$ & Acupuncture + RICE & RICE & Not reported & 14 days & $\begin{array}{c}\text { Effective rate, cure } \\
\text { rate }\end{array}$ \\
\hline $\begin{array}{l}\text { Wu and } \\
\text { Chen } \\
{[15]}\end{array}$ & 2017 & $42 / 40$ & Acupuncture + massage & Massage & $\begin{array}{l}\text { Once two } \\
\text { days }\end{array}$ & 14 days & $\begin{array}{l}\text { VAS, ankle } \\
\text { circumference, use } \\
\text { of painkiller }\end{array}$ \\
\hline Wu [16] & 2018 & $45 / 45$ & $\begin{array}{c}\text { Acupuncture + RICE (plaster } \\
\text { immobilization) }\end{array}$ & $\begin{array}{l}\text { RICE (plaster } \\
\text { immobilization) }\end{array}$ & $\begin{array}{l}\text { Once two } \\
\text { days }\end{array}$ & 21 days & $\begin{array}{l}\text { Effective rate, cure } \\
\text { rate, VAS }\end{array}$ \\
\hline $\operatorname{Li}[17]$ & 2018 & $40 / 40$ & $\begin{array}{l}\text { Acupuncture }+ \text { Chinese } \\
\text { medicine (shexiang zhuanggu } \\
\text { emplastrum) }\end{array}$ & $\begin{array}{l}\text { Chinese medicine } \\
\text { (shexiang zhuanggu } \\
\text { emplastrum) }\end{array}$ & Once a day & 10 days & $\begin{array}{c}\text { Effective rate, cure } \\
\text { rate, duration of } \\
\text { pain }\end{array}$ \\
\hline
\end{tabular}

E, experimental group; C, control group; RICE, Rest, Ice, Compression, and Elevation; VAS, visual analogue scale.

3.8. Ankle Circumference. Wu et al. [15] reported that ankle circumference was not statistically different after acupuncture plus massage treatment compared with massage alone $(n=82, \mathrm{MD}=-0.65,95 \% \mathrm{CI}:-1.64$ to $0.34, P=0.20)$. Li [12] found that the difference of ankle circumference between the uninjured and injured ankle was not statistically different after acupuncture treatment compared with RICE $(n=60$, $\mathrm{MD}=0.24,95 \% \mathrm{CI}:-0.10$ to $0.58, P=0.17)$.
3.9. Effective Rate. Fifteen studies reported the effective rate. It is defined as a ratio of the number of patients labelled as cure, excellent, or effectivity divided by the number of patients in a certain group. $\mathrm{Wu}$ [28] found that the effective rate in the acupuncture group was statistically higher $(P=0.0002)$ than that in no treatment group (Figure 4$)$. However, the effective rate in the acupuncture group was not different statistically from that in massage $(P=1.00)$, "Ice 


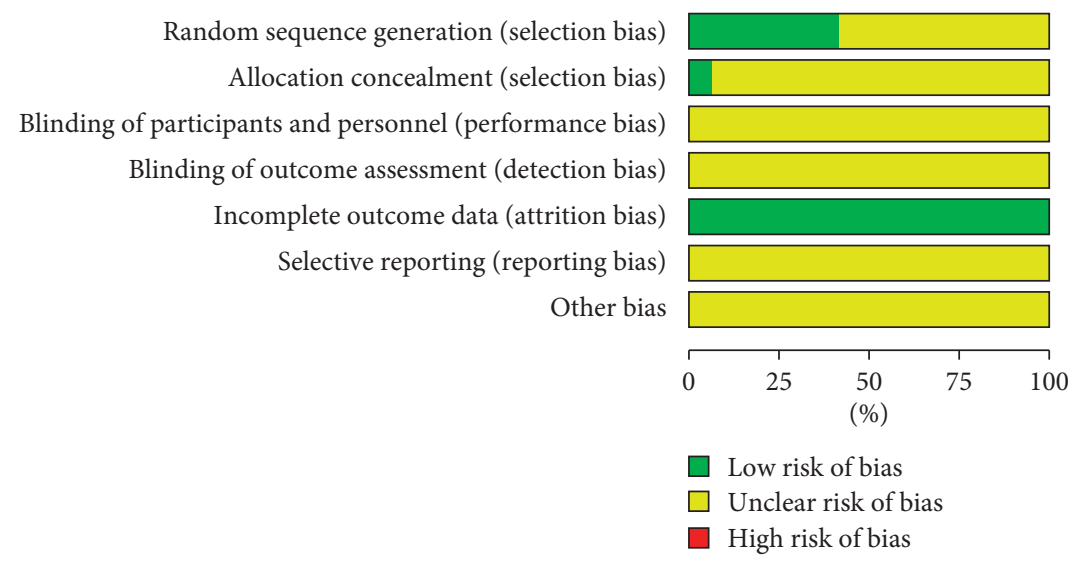

FIGURE 2: Risk of bias graph.

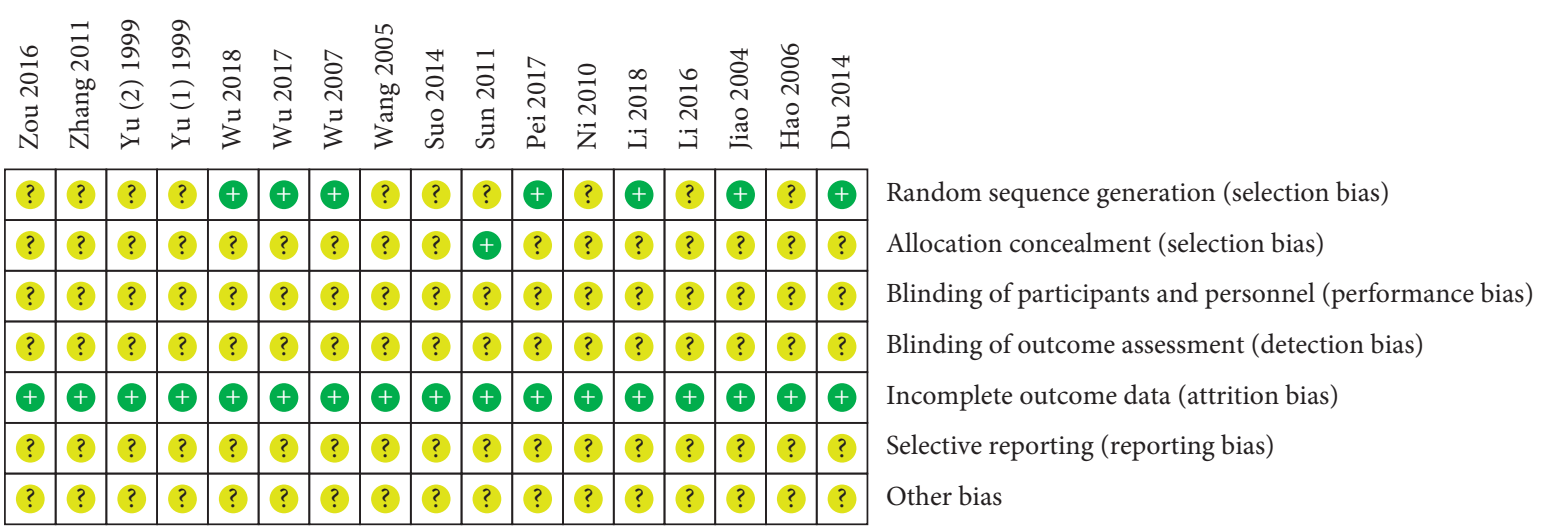

FIGURE 3: Risk of bias summary.

and hot pack" plus Chinese medicine $(P=0.07)$, infrared radiation $(P=0.51)$, or RICE $(P=1.00)$ group. A metaanalysis showed that dimethyl sulfoxide could significantly increase the effective rate compared with acupuncture $(P=0.03)$. Yu [24] found that the effective rate in the acupuncture plus dimethyl sulfoxide group was statistically higher $(P=0.04)$ than that in the dimethyl sulfoxide group (Figure 5). The results from meta-analyses showed that the effective rate in the acupuncture plus Chinese medicine or acupuncture plus RICE group was not different statistically from that in Chinese medicine $(P=0.14)$ or RICE group $(P=0.64)$. Moreover, Du et al. [11] reported that the effective rate in the acupuncture plus massage group was similar $(P=1.00)$ with that in the massage group.

3.10. Cure Rate. Thirteen studies reported the cure rate. It is defined as a ratio of the number of patients labelled as cure divided by the number of patients in a certain group. Figure 6 shows that the cure rate in the acupuncture group is statistically higher than that in the no treatment $(P=0.08)$, infrared radiation $(P=0.01)$, or RICE $(P=0.004)$ group. However, the cure rate in the acupuncture group was not statistically different from that in the massage $(P=0.52)$, or "Ice and hot pack" plus Chinese medicine $(P=0.10)$ group.

A meta-analysis showed that acupuncture plus Chinese medicine could significantly increase the cure rate
$(P=0.0002)$ compared with Chinese medicine alone (Figure 7). Other meta-analysis showed that acupuncture plus RICE could significantly increase the cure rate $(P=0.01)$ compared with RICE alone (Figure 8). Du et al. [11] found that the cure rate in the acupuncture plus massage group was higher ( $n=40, \mathrm{RR}=1.55,95 \% \mathrm{CI}: 1.00$ to $2.39, P=0.05$ ) than that in the massage group.

3.11. Adverse Events. Three included studies reported the information on adverse events. $\mathrm{Yu}$ [24] and $\mathrm{Wu}$ [28] reported no adverse reactions. Another study [23] reported that a participant suffered from mild drug-related allergic reaction and was healed without treatment.

3.12. Assessment of Publication Bias. No funnel plots were provided to assess publication bias because no meta-analyses involving more than ten studies were performed.

\section{Discussion}

4.1. Main Findings and Interpretation. The present study critically assessed the efficacy and safety of acupuncture for AAS. Overall, risk of bias assessment was limited because of incomplete reporting on risk of bias items. In view of the heterogeneity of interventions, main findings were interpreted based on comparisons between experimental and control groups. 


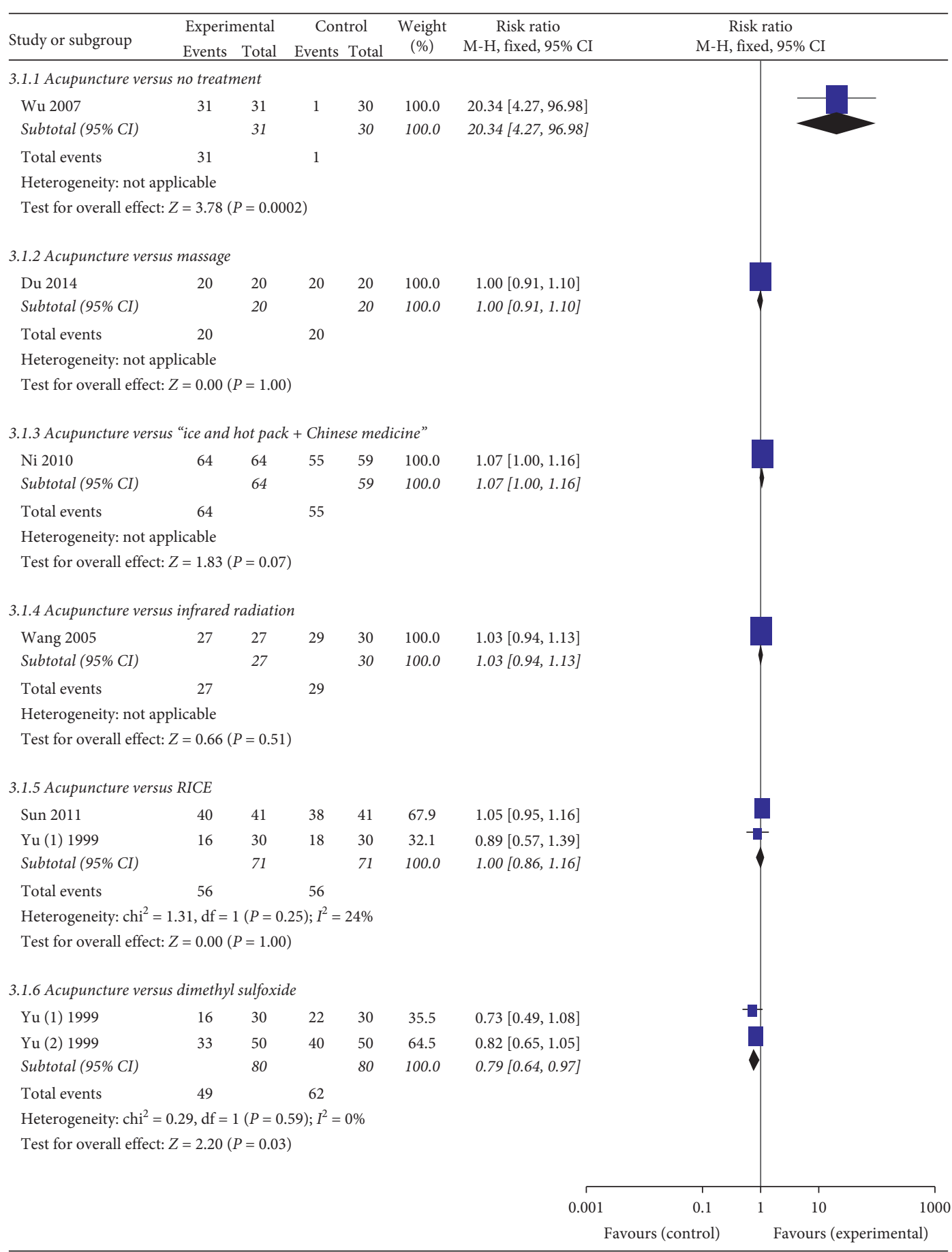

FIGURE 4: Forest plots of acupuncture versus other treatments on the effective rate.

Rest, ice, compression, and elevation (RICE) are generally used to treat acute ankle sprain in clinical practice [32]. However, a systematic review found insufficient evidence on RICE for AAS in adults [33]. RICE was also not recommended for the management of lateral ankle sprain according to a recent clinical guideline [4]. The present study found that acupuncture alone or in combination with RICE could significantly relieve pain and increase cure rate in patients with AAS compared with RICE alone. It suggests that acupuncture may be considered as a complementary and alternative therapy for treating AAS. However, more large-scale RCTs with objective outcomes are warranted to confirm these findings.

Massage belongs to nonpharmacological therapies and usually is used for the management of musculoskeletal disorders. A study found that massage might improve the flexibility and balance function of the ankle joint [34]. An evidence map showed that massage was used for treating a 


\begin{tabular}{|c|c|c|c|c|c|c|c|c|c|c|}
\hline \multirow{2}{*}{ Study or subgroup } & \multicolumn{2}{|c|}{ Experimental } & \multicolumn{2}{|c|}{ Control } & \multirow{2}{*}{$\begin{array}{c}\text { Weight } \\
(\%)\end{array}$} & \multirow{2}{*}{$\begin{array}{c}\text { Risk ratio } \\
\mathrm{M}-\mathrm{H}, \text { random, } 95 \% \text { CI }\end{array}$} & \multirow{2}{*}{\multicolumn{3}{|c|}{$\begin{array}{c}\text { Risk ratio } \\
\text { M-H, random, } 95 \% \text { CI }\end{array}$}} & \\
\hline & Events & Total & Events & Total & & & & & & \\
\hline \multicolumn{10}{|c|}{ 3.2.1 "Acupuncture + Chinese medicine" versus Chinese medicine } & \\
\hline Нао 2006 & 59 & 63 & 52 & 63 & 17.2 & $1.13[1.00,1.29]$ & & & & \\
\hline Jiao 2004 & 48 & 48 & 42 & 48 & 17.6 & $1.14[1.02,1.28]$ & & & & \\
\hline Li 2018 & 38 & 40 & 30 & 40 & 15.6 & $1.27[1.04,1.54]$ & & & & \\
\hline Suo 2014 & 35 & 36 & 31 & 35 & 17.2 & $1.10[0.96,1.25]$ & & & & \\
\hline Zhang 2011 & 90 & 90 & 70 & 70 & 18.9 & $1.00[0.98,1.03]$ & & & 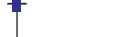 & \\
\hline Zou 2016 & 20 & 20 & 15 & 20 & 13.4 & $1.32[1.02,1.72]$ & & & & \\
\hline Subtotal (95\% CI) & & 297 & & 276 & 100.0 & $1.15[0.96,1.37]$ & & & & \\
\hline Total events & 290 & & 240 & & & & & & & \\
\hline \multicolumn{11}{|c|}{ Heterogeneity: $\operatorname{tau}^{2}=0.04 ; \mathrm{chi}^{2}=78.51, \mathrm{df}=5(P<0.00001) ; I^{2}=94 \%$} \\
\hline \multicolumn{11}{|c|}{ Test for overall effect: $Z=1.48(P=0.14)$} \\
\hline \multicolumn{11}{|c|}{ 3.2.2 "Acupuncture + dimethyl sulfoxide" versus dimethyl sulfoxide } \\
\hline Yu (2) 1999 & 47 & 50 & 40 & 50 & 100.0 & $1.18[1.01,1.37]$ & & & & \\
\hline Subtotal (95\% CI) & & 50 & & 50 & 100.0 & $1.18[1.01,1.37]$ & & & & \\
\hline Total events & 47 & & 40 & & & & & & & \\
\hline \multicolumn{11}{|c|}{ Heterogeneity: not applicable } \\
\hline \multicolumn{11}{|c|}{ Test for overall effect: $Z=2.04(P=0.04)$} \\
\hline \multicolumn{11}{|c|}{ 3.2.3 "Acupuncture + massage" versus massage } \\
\hline Du 2014 & 20 & 20 & 20 & 20 & 100.0 & $1.00[0.91,1.10]$ & & & & \\
\hline Subtotal (95\% CI) & & 20 & & 20 & 100.0 & $1.00[0.91,1.10]$ & & & & \\
\hline Total events & 20 & & 20 & & & & & & & \\
\hline \multicolumn{11}{|c|}{ Heterogeneity: not applicable } \\
\hline \multicolumn{11}{|c|}{ Test for overall effect: $Z=0.00(P=1.00)$} \\
\hline \multicolumn{11}{|c|}{ 3.2.4 "Acupuncture + RICE" versus RICE } \\
\hline Pei 2017 & 35 & 35 & 35 & 35 & 52.0 & $1.00[0.95,1.06]$ & & & & \\
\hline Wu 2018 & 41 & 45 & 32 & 45 & 48.0 & $1.28[1.04,1.58]$ & & & & \\
\hline Subtotal $(95 \%$ CI) & & 80 & & 80 & 100.0 & $1.13[0.69,1.85]$ & & & & \\
\hline Total events & 76 & & 67 & & & & & & & \\
\hline \multicolumn{11}{|c|}{ Heterogeneity: $\operatorname{tau}^{2}=0.12 ;$ chi $^{2}=21.37, \mathrm{df}=1(P<0.00001) ; I^{2}=95 \%$} \\
\hline \multicolumn{11}{|c|}{ Test for overall effect: $Z=0.47(P=0.64)$} \\
\hline & & & & & & & 0.7 & 0.85 & 1.2 & 1.5 \\
\hline & & & & & & & Favours & (control) & Favours (exp & erimental) \\
\hline
\end{tabular}

Figure 5: Forest plots of acupuncture plus other treatments versus other treatments on effective rate.

variety of pain conditions [35]. The present study found that acupuncture combined with massage could significantly relieve pain in patients with AAS compared with massage alone. However, the underlying mechanism of the combination for AAS is still poorly investigated.

Patients with AAS often experience acute pain and swelling associated with inflammatory reactions [36]. Previous studies showed that some Chinese medicines had antiinflammatory properties and were used for treating musculoskeletal disorders [37-39]. The present study found that acupuncture plus Chinese medicine might be more effective for relieving pain, reducing the duration of pain, and increasing cure rate than Chinese medicine alone in patients with AAS. Nonsteroidal anti-inflammatory drugs were recommended for reducing pain and controlling swelling in patients with acute lateral ankle sprain [4]. However, the efficacy of acupuncture versus nonsteroidal anti-inflammatory drugs for AAS was not assessed because no eligible trials were identified.
The present study provided some insights into the management of AAS. Combined-modality therapy may provide additional benefits in patients with AAS. These findings may be useful for updating clinical practice guidelines. Moreover, a review reported that acupuncture could relieve pain by activating acupoints and transmitting signals to the spinal cord and brain associated with the regulation of inflammatory factors [40]. An experiment showed that acupuncture might relieve neuropathic pain in rats by inhibiting microglial activation and inflammatory responses [41]. Chen et al. [42] found that acupuncture might relieve inflammatory symptoms at the ankle joint by reducing serum TNF- $\alpha$ and anti-cyclic citrullinated peptide antibody levels. The evidence may partly explain why acupuncture may be effective for AAS.

4.2. Limitations. This systematic review had several limitations. Firstly, effect size might be overestimated because of 


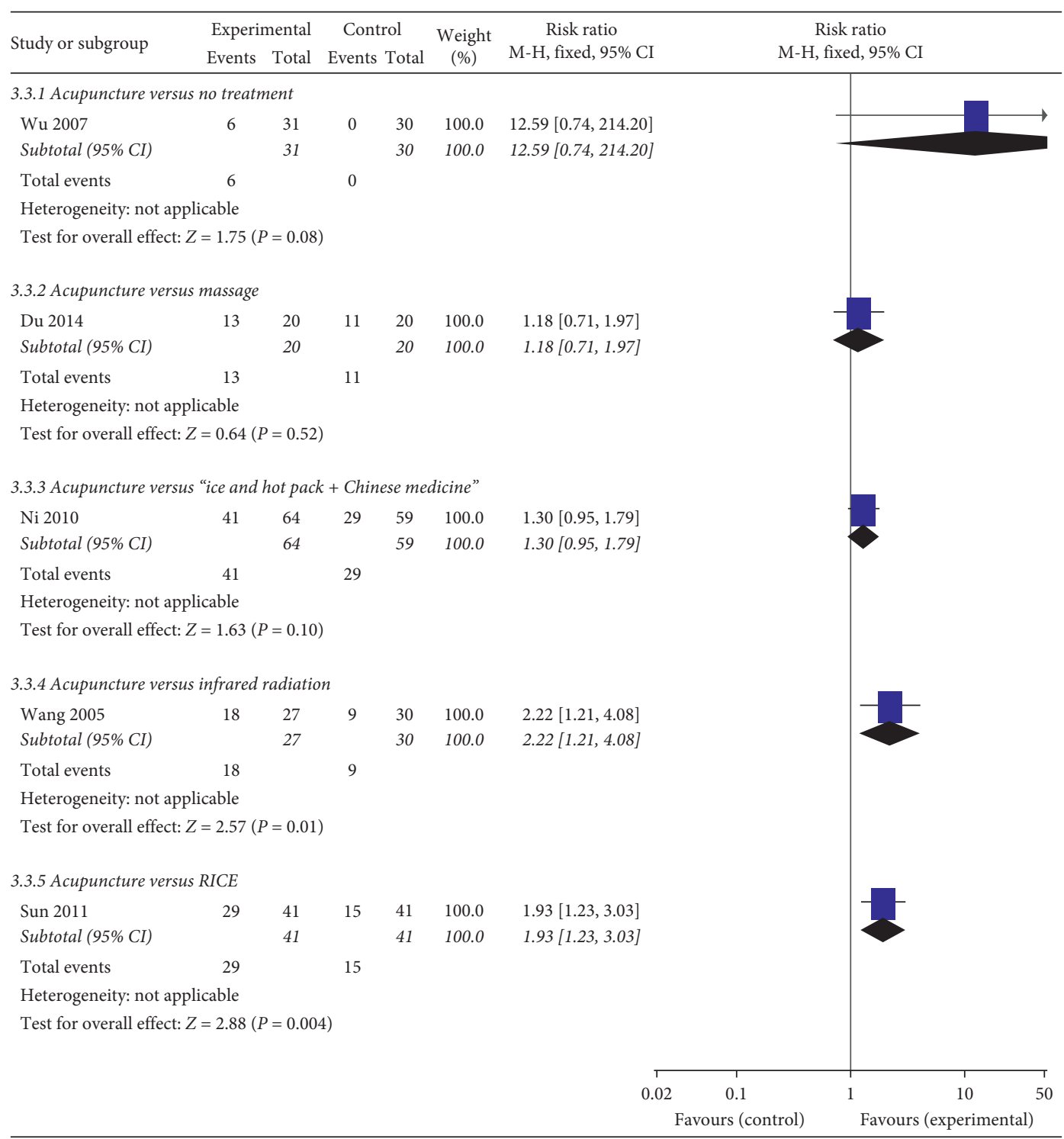

FIGURE 6: Forest plots of acupuncture versus other treatments on cure rate.

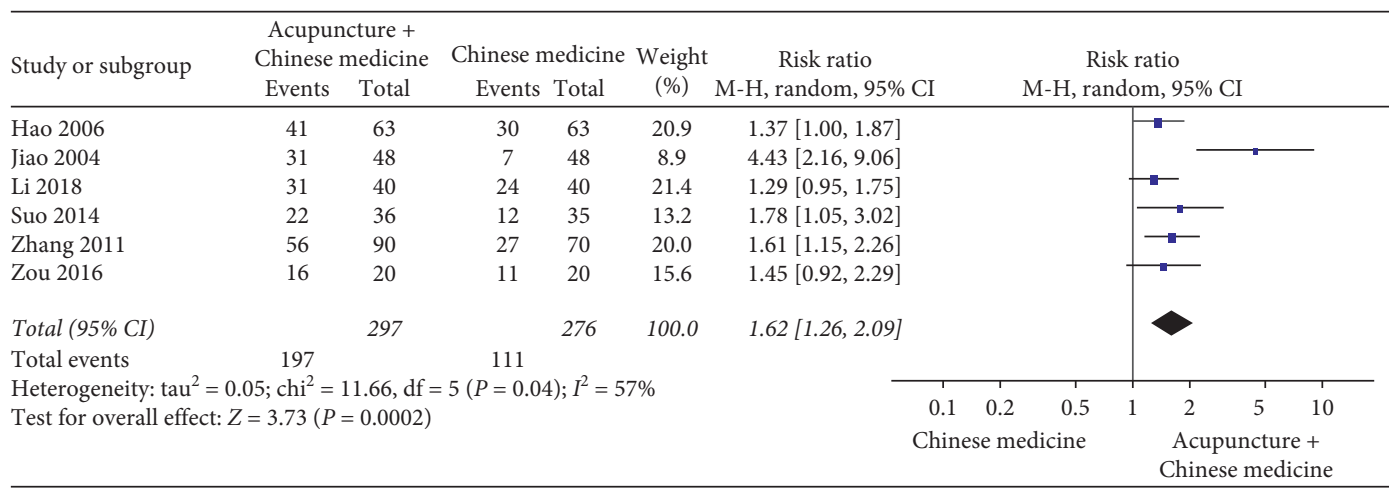

Figure 7: Forest plot of acupuncture plus Chinese medicine versus Chinese medicine on cure rate. 


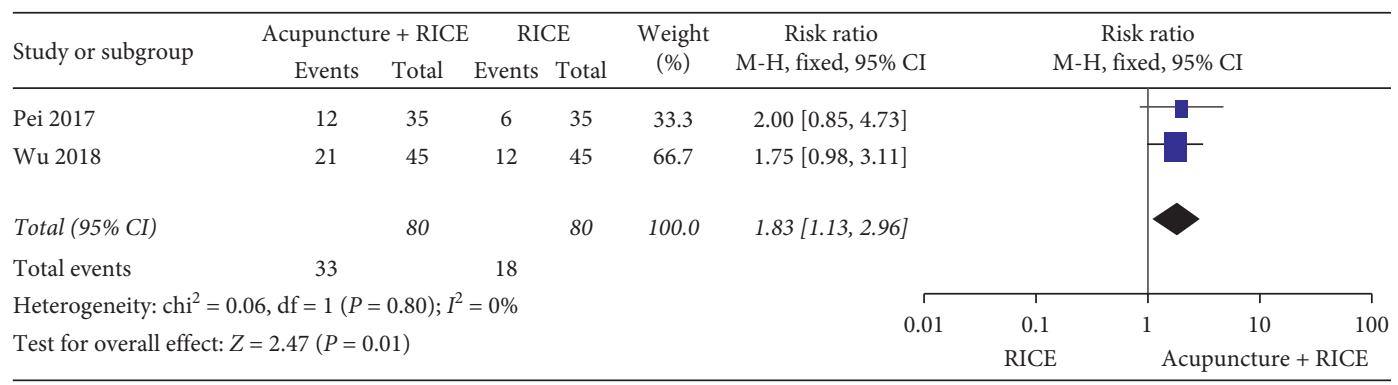

FIGURE 8: Forest plot of acupuncture plus RICE versus RICE on cure rate.

small sample size. Secondly, performing the meta-analysis was limited because of the heterogeneity of interventions. Thirdly, the results should be interpreted cautiously because of methodological flaws and rarely reported objective outcomes in included studies.

\section{Conclusions}

The findings of the present study suggest that acupuncture may be beneficial for AAS. However, more large-scale and well-designed RCTs are warranted.

\section{Data Availability}

All datasets presented in this study are included in the article or supplementary material.

\section{Disclosure}

AFL and SWG are considered as co-first authors. AFL and JBZ are considered as corresponding authors.

\section{Conflicts of Interest}

The authors declare that they have no conflicts of interest.

\section{Authors' Contributions}

AFL and JBZ conceived the study. SWG and AFL designed the protocol. SWG and AFL searched and selected studies. JXC and SWG extracted data and assessed the risk of bias. JBZ performed statistical analysis. AFL and SWG drafted the manuscript. JBZ reviewed and revised the manuscript. All authors have read and approved the final version of the manuscript. AFL and SWG contributed equally to this work.

\section{Acknowledgments}

This work was supported by the National Natural Science Foundation of China (grant no. 81873316).

\section{Supplementary Materials}

Detailed search strategy is shown in the Supplementary Material. (Supplementary Materials)

\section{References}

[1] J. Park, S. Hahn, J. Y. Park, H. J. Park, and H. Lee, "Acupuncture for ankle sprain: systematic review and metaanalysis," BMC Complement Alternative Medicine, vol. 13, Article ID 55, 2013.

[2] D. T.-P. Fong, Y. Hong, L.-K. Chan, P. S.-H. Yung, and K.-M. Chan, "A systematic review on ankle injury and ankle sprain in sports," Sports Medicine, vol. 37, no. 1, pp. 73-94, 2007.

[3] C. Doherty, E. Delahunt, B. Caulfield et al., "The incidence and prevalence of ankle sprain injury: a systematic review and meta-analysis of prospective epidemiological studies," Sports Medicine, vol. 44, no. 1, pp. 123-140, 2014.

[4] G. Vuurberg, A. Hoorntje, L. M. Wink et al., "Diagnosis, treatment and prevention of ankle sprains: update of an evidence-based clinical guideline," British Journal of Sports Medicine, vol. 52, no. 15, Article ID 956, 2018.

[5] C. Doherty, C. Bleakley, E. Delahunt, and S. Holden, "Treatment and prevention of acute and recurrent ankle sprain: an overview of systematic reviews with meta-analysis," British Journal of Sports Medicine, vol. 51, no. 2, pp. 113-125, 2017.

[6] E. T. Chen, J. Borg-Stein, and K. C. Mcinnis, "Ankle sprains: evaluation, rehabilitation, and prevention," Current Sports Medicine Reports, vol. 18, no. 6, pp. 217-223, 2019.

[7] A. Xiang, K. Cheng, X. Shen, P. Xu, and S. Liu, "The immediate analgesic effect of acupuncture for pain: a systematic review and meta-analysis," Evidence Based Complement Alternative Medicine, vol. 2017, Article ID 3837194, 2017.

[8] S. Patil, S. Sen, M. Bral et al., "The role of acupuncture in pain management," Current Sports Medicine Reports, vol. 20, no. 4, Article ID 22, 2016.

[9] T. H. Kim, M. S. Lee, K. H. Kim et al., "Acupuncture for treating acute ankle sprains in adults," Cochrane database of systematic reviews, vol. 6, Article ID CD009065, 2014.

[10] L. W. Q. Suo, "Study on the effect of acupuncture treatment of acute ankle sprain," Contemporary Medicine Forum, vol. 12, no. 12 , pp. 50-51, 2014.

[11] W. B. Du, G. A. Bao, and R. F. Quan, "Impacts on analgesia and detumescence in ankle sprain treated with acupuncture at Xiaojie point combined with tendon-regulation manipulation," Chin Acup Moxib, vol. 34, no. 7, pp. 647-650, 2014.

[12] K. Li, Clinical Study on the Curative of Contralateral Acupuncture on Acute Sprain of Ankle, Master's Thesis, Guangzhou University of Chinese Medicine, Guangzhou, China, 2016.

[13] S. Q. Zou, B. Q. Li, and H. L. Pan, "Clinical observation on acupuncture combined with sunshang emplastrum for acute ankle sprain," Inner Mongolia Journal of Traditional Chinese Medicine, vol. 11, pp. 128-129, 2016. 
[14] C. Q. Pei and Y. Wei, "Analysis of the efficacy of joint-corresponding point selection plus exercise acupuncture in treating acute ankle sprain," Shanghai J Acu-Mox, vol. 36, no. 4, pp. 464-466, 2017.

[15] C. Q. Wu and M. Chen, "Clinical observation on juci acupuncture combined with massage for acute ankle sprain," Journal of Clinical Acupuncture and Moxibustion, vol. 33, no. 2, pp. 25-27, 2017.

[16] S. C. Wu, M. C. You, P. Yu et al., "Acupuncture combined with plaster immobilization for acute ankle sprain," AsiaPacific Traditional Medicine, vol. 14, no. 9, pp. 164-166, 2018.

[17] S. Li, Y. Z. Zhang, and J. Y. Liu, "Analysis of therapeutic effect of acupuncture on patients with acute ankle sprain," Clinical Journal of Traditional Chinese Medicine, vol. 30, no. 7, pp. 1298-1300, 2018.

[18] D. Moher, A. Liberati, J. Tetzlaff, and D. G. Altman, "Preferred reporting items for systematic reviews and meta-analyses: the PRISMA statement," PLoS Medicine, vol. 6, no. 7, Article ID e1000097, 2009.

[19] H. Koivu, I. Kohonen, K. Mattila, E. Loyttyniemi, and H. Tiusanen, "Long-term results of scandinavian total ankle replacement," Foot Ankle International, vol. 38, no. 7, pp. 723-731, 2017.

[20] L. M. De-Regil, J. P. Peña-Rosas, A. C. Fernández-Gaxiola, and P. Rayco-Solon, "Effects and safety of periconceptional oral folate supplementation for preventing birth defects," Cochrane Database Systems Review, vol. 12, Article ID CD007950, 2015.

[21] J. P. T. Higgins, J. Thomas, J. Chandler et al., Cochrane Handbook for Systematic Reviews of Interventions Version 6.0, Cochrane, London, UK, 2019.

[22] L. L. Ma, Y. Y. Wang, Z. H. Yang et al., "Methodological quality (risk of bias) assessment tools for primary and secondary medical studies: what are they and which is better?" Military Medical Research, vol. 7, no. 1, Article ID 7, 2020.

[23] J. Yu, "A report of dimethyl sulfoxide gel, ice compress and acupuncture for treating 30 patients with ankle sprain," Chinese Journal of Sports Medicine, vol. 18, no. 3, pp. 279-280, 1999.

[24] J. Yu, "Observation on the effect of acupuncture combined with dimethyl sulfoxide gel for ankle sprain," Natural Science Journal of Hainan University, vol. 17, no. 4, pp. 374-375, 1999.

[25] H. Jiao and H. Wang, "Clinical observation of sprain of the ankle joint treated with acupuncture and moxibustion under TDP irradiating," Acta Academiae Medicinae CPAPF, vol. 13, no. 5, pp. 399-400, 2004.

[26] X. L. Wang, "Observation of the effect of electroacupuncture for lateral ankle ligament sprain," Modern Journal of Integrated Traditional Chinese and Western Medicine, vol. 14, no. 2, p. 168, 2005.

[27] H. M. Hao and X. Wang, "Clinical observation of acupuncture combined with Chinese medicine for 63 patients with ankle sprain," Journal of Shanxi College of Traditional Chinese Medicine, vol. 7, no. 4, pp. 29-30, 2006.

[28] Z. S. Wu, Clinical Study and Evaluation of the Efficacy of Blood-Pricking Therapy for Acute Ankle Sprain, Master's Thesis, Beijing University of Chinese medicine, Beijing, China, 2007.

[29] X. P. Ni and Y. J. Li, "Observation of Clinical Efficacy of needing xiaojie point for sprain of ankle joints," Inner Mongolia Journal of Traditional Chinese Medicine, vol. 18, p. 38, 2010.
[30] C. Sun and Y. Y. Ju, "Evaluation on the effect of acupuncture in the acute ankle sprain induced by football," Modern Preventive Medicine, vol. 38, no. 10, pp. 1890-1891, 2011.

[31] L. Zhang and Y. P. Zhang, "Treating 90 cases of acute ankle sprain of students by combination therapy," Clinical Journal of Chinese Medicine, vol. 3, no. 22, pp. 113-114, 2011.

[32] T. W. Kaminski, J. Hertel, N. Amendola et al., "National athletic trainers' association position statement: conservative management and prevention of ankle sprains in athletes," The Journal of Athletic Training, vol. 48, no. 4, pp. 528-545, 2013.

[33] M. P. van den Bekerom, P. A. Struijs, L. Blankevoort et al., "What is the evidence for rest, ice, compression, and elevation therapy in the treatment of ankle sprains in adults?" The Journal of Athletic Training, vol. 47, no. 4, pp. 435-443, 2012.

[34] J. Park, J. Shim, S. Kim et al., "Application of massage for ankle joint flexibility and balance," The Journal of Physical Therapy Science, vol. 29, no. 5, pp. 789-792, 2017.

[35] I. M. Miake-Lye, S. Mak, J. Lee et al., "Massage for pain: an evidence map," Journal of Alternative and Complementary Medicine, vol. 25, no. 5, pp. 475-502, 2019.

[36] D. Carter and J. Amblum-Almer, "Analgesia for people with acute ankle sprain," Emergency Nursing, vol. 23, no. 1, pp. 24-31, 2015.

[37] Y. H. Wang and K. W. Zeng, "Natural products as a crucial source of anti-inflammatory drugs: recent trends and advancements," Traditional Medicine Research, vol. 4, no. 5, pp. 257-268, 2019.

[38] H. H. Ryu, J. C. Kang, U. Namgung, S. Y. Kim, and J. Y. Park, "Anti-inflammatory effects of modified buyang huanwu decoction," Evidance Based Complementary Alternative Medicine, vol. 2020, Article ID 6458460, 2020.

[39] K. Zheng, Z. Chen, W. Sun et al., "Hei-gu-teng zhuifenghuoluo granule modulates IL-12 signal pathway to inhibit the inflammatory response in rheumatoid arthritis," Journal of Immunology Research, vol. 2018, Article ID 8474867, 2018.

[40] T. Chen, W. W. Zhang, Y. X. Chu, and Y. Q. Wang, "Acupuncture for pain management: molecular mechanisms of action," American Journal of Chinese Medicine, vol. 48, no. 4, pp. 793-811, 2020.

[41] D. C. Choi, J. Y. Lee, E. J. Lim et al., "Inhibition of ROSinduced p38MAPK and ERK activation in microglia by acupuncture relieves neuropathic pain after spinal cord injury in rats," Experimental Neurology, vol. 236, no. 2, pp. 268-282, 2012.

[42] T. W. Chen, Y. Yin, R. Zhang, and W. Z. Ma, "Fire-needle acupuncture intervention relieves ankle-joint inflammatory reactions possibly by down-regulating serum TNF- $\alpha$ and anticyclic citrullinated peptide antibody levels in collagen-induced Arthritis.Rats," Zhen Ci Yan Jiu, vol. 43, no. 8, pp. 501-505, 2018. 